\title{
MEJORA GENÉTICA PARTICIPATIVA DE LA VARIEDAD CRIOLLA DE FRIJOL "SACAPOBRES"1
}

\author{
Rodolfo Araya-Villalobos ${ }^{2}$, Juan Carlos Hernández-Fonseca ${ }^{3}$
}

\begin{abstract}
RESUMEN
Mejora genética participativa de la variedad criolla de frijol "Sacapobres". Agricultores experimentadores de la Región Brunca de Costa Rica solicitaron en el año 1999, al Programa de Investigación y Transferencia de Tecnología Agropecuaria en frijol (PITTA Frijol), la mejora genética de la variedad criolla Sacapobres, una de las principales variedades criollas de la Región Brunca, que posee precocidad (60 días a cosecha, superando en más de diez días a la variedad mejorada más precoz) y alto potencial de rendimiento en grano (no había podido ser sustituida por las variedades mejoradas en sus campos de producción), pero de alta emisión de guías y acame. En el Centro Internacional de Agricultura Tropical (CIAT) y la Escuela Agrícola Panamericana Zamorano, se efectuaron hibridaciones con esta variedad criolla. La selección de los materiales segregantes se inició en los años 2000 y 2001, en Costa Rica y se basó en la metodología de fitomejoramiento participativo (FP). Los sitios de selección fueron fincas de agricultores y una estación experimental. El principal criterio empleado por los agricultores fue la arquitectura erecta (ausencia o poca emisión de guías y sin acame) para facilitar el tránsito por el terreno en las labores de deshierba y fumigación, seguido del tipo, tamaño y color de grano e incidencia de patógenos. Se seleccionaron, en el año 2005, dos líneas promisorias, que pasarán a la etapa de validación. Se describe la estrategia de selección en FP, la genealogía de los progenitores empleados y se concluye sobre el futuro mejoramiento de Sacapobres.
\end{abstract}

Palabras clave: Variedad criolla, fitomejoramiento participativo, asociación de productores, Phaseolus vulgaris, experimentación campesina.

\begin{abstract}
Participative breeding of the local bean variety "Sacapobres" in Costa Rica. Experienced farmers from the Brunca Region in Costa Rica requested to the PITTA frijol program the genetic improvement of the local variety "Sacapobres", one of the main local varieties of this region, characterized by its precocity (60 days to harvest, at least 10 days earlier than the most precocious bred lines) and high yield potential (because of what could not be substituted by bred varieties), but susceptible to lodging and prone to produce excessive indeterminate growth. Crosses involving Sacapobres were performed at CIAT and Zamorano, and the selection of the segregating materials was started in Costa Rica during years 2000 and 2001, using the participative breeding methodology. Selection took place in bean producers' farms and in an experiment station. The main criterion used by farmers to select the lines was the presence of erect plant architecture that eases circulation in the field, weeding, and fumigations. Other criteria were type, size and color of the seed, as well as susceptibility to disease. Two promising lines were selected in year 2005, which were used in a second phase of validation trials. We describe the selection strategy followed during participative breeding, the genealogy of the parents employed, and draw conclusions on the future of the Sacapobres variety.
\end{abstract}

Key words: Local variety, participative breeding, producers association, Phaseolus vulgaris, on-farm research.

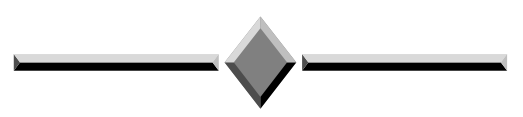

1 Recibido: 7 de junio, 2006. Aceptado: 14 de agosto, 2006. Proyecto Vicerrectoría de Investigación \# 736-91-315, Universidad de Costa Rica

2 Estación Experimental Fabio Baudrit Moreno, Universidad de Costa Rica. Apartado postal 2645-3000. Heredia, Costa Rica. Correo electrónico: avillalo@cariari.ucr.ac.cr

3 Instituto Nacional de Innovación y Transferencia en Tecnología Agropecuaria (INTA). San José, Costa Rica. Correo electrónico: j.hernandez@costarricense.cr 


\section{INTRODUCCIÓN}

En Costa Rica hasta el año de 1995, se aplicó el método de mejoramiento genético convencional (FC) y la mayoría del proceso de selección de variedades se había efectuado en el Valle Central y en su mayoría en estación experimental, (condiciones y ambiente diferente a la de las zonas productoras) (Araya 1998). Se ha evidenciado la poca adaptación de las variedades mejoradas a los microambientes de las zonas productoras, debido a la falta de características agronómicas requeridas por los agricultores, lo que ha influido en su baja adopción. Los agricultores de la Región Brunca manifiestan la necesidad de disponer de variedades mejoradas precoces, y con arquitectura erecta, que permita una condición menos apropiada para la incidencia de patógenos, facilite el control de malezas, y la aplicación de agroquímicos. Desean también variedades de mayor rendimiento (superior a $1.000 \mathrm{~kg} / \mathrm{ha}$ ) y con poco empleo de agroquímicos.

En la actualidad la mayoría del proceso de selección de materiales segregantes, se efectua bajo las mismas condiciones ambientales y de manejo agronómico de las áreas comerciales y con la participación de los agricultores en la selección de segregantes o líneas avanzadas, metodología conocida como fitomejoramiento participativo (FP) (Ashby 1993; Araya y Hernández 2001; Araya et al. 2002). El FP es una alternativa no sólo viable, sino rentable y adaptada a las condiciones ambientales y de manejo de los pequeños productores (Almekinders y Elings 2001; Ashby et al. 1995; Araya y Hernández 2001; Hocdé et al. 1999b; Rosas 2001). El FP es un método de selección de materiales más efectivo en generar variedades de frijol estables, de alta productividad y de mayor adopción (Hernández y Araya 2003; Hernández y Araya 2004; Rosas et al. 2003).

La participación de los agricultores en el Fitomejoramiento Participativo, en estación experimental, les permite involucrarse en la selección de una diversidad genética amplia y un elevado número de variedades, líneas o segregantes que no es posible sembrar en las fincas de los agricultores por el espacio disponible para las siembras comerciales, la irregularidad de los terrenos en pendiente y fertilidad; condiciones que pueden influir en el desarrollo de las pequeñas parcelas, además de los riesgos por causas de sequías o temporales. Aunque las condiciones de estación experimental difieren de la de los agricultores, se puede avanzar en la selección por arquitectura, tono de color rojo y forma de grano, y se puede inocular artificialmente, para determinar resistencia o tolerancia de las variedades a diversos patógenos.

Las principales actividades agropecuarias de la región Brunca son el maíz, el frijol, el café y la ganadería. Veracruz de Pejibaye (altitud de $550 \mathrm{msnm}$ ) y Concepción de Pilas $(640 \mathrm{~m}$ ) son dos comunidades de gran importancia productiva. Cuentan con unos 400 agricultores, que siembran aproximadamente 2.000 ha de frijol, 730 ha de maíz, y unas 300 ha de arroz. El área promedio por agricultor varía entre 1 a 5 ha para el cultivo del frijol, 2 ha para maíz y 0,2 ha para arroz, el sistema de siembra es manual a espeque. Cerca del $100 \%$ de los productores cultivan granos básicos en sus sistemas de producción, en áreas que no exceden las 5 ha, en terrenos con altas pendientes. Sobresale el uso de diversos materiales de frijol al mismo tiempo, tanto variedades rojas como negras. La mayor parte de las áreas sembradas son de variedades de grano de color rojo debido a los mejores precios ofertados al grano rojo en los últimos años. El agricultor siembra también variedades de color negro, principalmente para su propio consumo.

En Pejibaye y Pilas, el clima se clasifica como tropical lluvioso, presenta zonas bioclimáticas que incluyen Bosque Muy Húmedo Tropical, en terrenos altos; Bosque Húmedo Tropical, en los terrenos más bajos, y Bosque Húmedo Tropical de Transición a Seco, en el pie de los montes de la Fila Costeña. La temperatura promedio es de 22 a $23{ }^{\circ} \mathrm{C}$, con temperaturas máximas promedio de $28{ }^{\circ} \mathrm{C}$ y mínimas de $18{ }^{\circ} \mathrm{C}$; la humedad relativa se estima en un 86 a $88 \%$ para los meses entre septiembre y diciembre. La precipitación promedio anual varía entre 1.700 y $1.800 \mathrm{~mm}$, con dos estaciones claramente diferenciadas; la lluviosa (abril a noviembre) y la seca (diciembre a marzo). En el mes de julio se presenta una disminución en la precipitación durante la cual los productores hacen la cosecha del frijol.

En la Región Brunca de Costa-Rica, en el periodo 1990-1994 se formaron varias asociaciones de productores (ASOPROS) con el objetivo de mejorar su capacidad para comercializar granos. Luego de esa etapa se 
crearon los comités de comercialización, acopio, crédito, y otros para proyectos específicos. Con el Programa Regional de Reforzamiento a la Investigación Agronómica sobre Granos en Centroamérica (PRIAG) se fortaleció su capacidad de experimentación cuando crearon comités técnicos de experimentación (llevaron ensayos en fertilización, producción local de semilla, control de plagas y enfermedades e introducción de leguminosas de cobertura). Este proceso condujo después a una motivación e incorporación de los agricultores dentro del proceso de mejora genética, que inició en el año 1995. Como resultado de este proceso se liberó Bribri, la primera variedad comercial de Costa Rica, obtenida con la participación de agricultores (FP), fue evaluada en sus fincas y bajo el manejo agronómico local. La presencia de las ASOPROS facilita el trabajo de investigación y transferencia de tecnología.

La variedad criolla de frijol Sacapobres, utilizada por los aborígenes de Boruca de Costa Rica y luego adoptada por agricultores colonizadores de las áreas aledañas donde habitan estos aborígenes, debido a su adaptación edafoclimática, principalmente en Pejibaye de Pérez Zeledón, adecuada al sistema de frijol tapado (Araya y González 1987; Hocdé et al. 1999a), y de gran precocidad.

Las ASOPROS de Concepción de Pilas y Veracruz propusieron en el año 1999, al Programa de Investigación y Transferencia de Tecnología Agropecuaria en Frijol (PITTA-Frijol), que los investigadores generarán un Sacapobres mejorado (Hocde et al. 1999a), con base en los siguientes criterios: no había una variedad mejorada con un ciclo vegetativo tan precoz como Sacapobres. La variedad Sacapobres era similar o superior en producción de grano a las variedades mejoradas, evaluadas en sus sitios de producción comercial (Morales 19947; Mora 19958), mostraba un hábito de crecimiento de mucha emisión de guías, que tiende a dificultar el tránsito por el campo para ejecutar labores de deshierba y protección agroquímica, por lo que necesitaban una

7 MORALES, A. 1994. Ensayos de verificación de cultivares promisorios de frijol. Ministerio de Agricultura y Ganadería (MAG), San José, Costa Rica .Comunicación personal.

8 MORA, B. 1995. Validación de cultivares mejorados de frijol común en diferentes localidades de Pejibaye en la época inverniz de 1995. Ministerio de Agricultura y Ganadería (MAG), San José, Costa Rica. Comunicación personal. variedad de arquitectura erecta y poca emisión de guías, era más atacada por antracnosis (Colletotrichum lindemuthianum), mancha angular (Phaeoisariopsis griseola) y mustia hilachosa (Thanatephorus cucumeris), con respecto a las variedades mejoradas.

El objtivo de esta investigación fue obtener nuevos cultivares de frijol de grano rojo, que superen a la variedad criolla Sacapobres, con base en desarrollo de lineas experimentales provenientes de hibridación, con el empleo de Sacapobres y diversos progentitores.

\section{MATERIALES Y MÉTODOS}

El PITTA Frijol solicitó la colaboración del Dr. Juan Carlos Rosas de la Escuela Agrícola Panamericana Zamorano y del Dr. Steve Beebe del Programa de Frijol del Centro Internacional de Agricultura Tropical (CIAT), para la selección de progenitores y la realización de cruzas con la variedad Sacapobres. En Zamorano, se seleccionaron progenitores que pudieran aportar arquitectura erecta y tolerancia a patógenos (antracnosis, mustia hilachosa y mancha angular), como Tío Canela, Bribri y Cabécar.

El Centro Internacional de Agricultura Tropical (CIAT) proporcionó una diversidad de progenitores cada uno con sus características propias: unos genotipos eran tolerantes al virus del mosaico dorado por incluir los genes bc 3 y bgm1 (9825-49-3), otros tolerantes a la inundación o a la baja fertilidad y con buen potencial producción de grano (A 774), otros tolerantes a la baja fertilidad, con buena arquitectura y calidad de grano ( $G$ 21212), otros resistentes a la mancha angular y con buena producción de grano (A 247), otros tolerantes a la mancha angular (G4691 y MAR 1 (hábito III)), grano de color rojo comercial, otro tolerante a la mancha angular (G 10474), otros presentaban una resistencia múltiple a antracnosis, bacteriosis y mancha angular (A 801), con una arquitectura y porte erecto (Tío Canela).

La hibridación múltiple se efectuó en los invernaderos y a nivel de campo experimental en el CIAT y en la Escuela Agrícola Panamericana Zamorano.

La mejora genética participativa se llevó a cabo con las ASOPROs de Concepción de Pilas de Buenos 
Aires, Veracruz de Pejibaye y Pueblo Nuevo de Upala, las cuales tienen una sólida trayectoria organizativa. El grupo involucrado en el proyecto estuvo constituido por productores de granos, que han participado en acciones de experimentación, bajo la coordinación de sus comités técnicos de experimentación, generalmente conformados por tres o cuatro productores.

En el Cuadro 1, se describe la genealogía de las poblaciones que dieron inicio a la mejora genética de la variedad criolla Sacapobres, la cantidad de materiales evaluados y los años de evaluación.

Como variedades testigo, se seleccionaron la variedad comercial Bribri, que es estable en su arquitectura y poca emisión de guías tanto en la Región Brunca como en Alajuela y la Región Huetar Norte, y la variedad criolla Sacapobres, para determinar el grado de avance en arquitectura, precocidad y rendimiento.

Los comités técnicos de experimentación de cada ASOPRO propusieron los sitios de experimentación en las fincas de agricultores, seleccionaron los agricultores encargados del manejo de los ensayos y aquellos que efectuarían las evaluaciones. En la estación experimental se inició la mayoría de las evaluaciones de segregantes.

La mejora genética de la variedad criolla Sacapobres se llevó a cabo mediante una selección, por lo general, alternada entre estación experimental y finca de agricultor. El tamaño de la parcela en poblaciones varió entre $90 \mathrm{~m}^{2}$ y $150 \mathrm{~m}^{2}$. En familias el tamaño de la parcela varió de $20 \mathrm{~m}^{2}$ a $50 \mathrm{~m}^{2}$. En las líneas, las parcelas fueron de dos hileras de $4 \mathrm{~m}$ de largo, con dos repeticiones. En el Cuadro 2, se muestran los sitios donde se fue alternando la selección de segregantes.

Se suministró a los agricultores una tabla con el código de cada población, familia o línea, un espacio para colocar una calcamonía en el material seleccionado, y el técnico anotó los comentarios positivos o negativos sobre el material. Luego de cada trabajo de selección en campo (madurez fisiológica y cosecha), se efectuó una sesión de salon, donde se discutieron los criterios que influyeron en la selección de cada material. Los materiales seleccionados en esta etapa, fueron los que obtuvieron más votos. Esta selección sirvió de referencia para, la elección final de los materiales promisorios con base en su rendimiento.
La mayoría de las selecciones de segregantes se inició en la estación experimental, debido al alto número de materiales por evaluar, poca semilla disponible y los riesgos de pérdida en finca de agricultores. En el Cuadro 3, se muestran todos los criterios de selección de los agricultores y fitomejoradores, pero la principal eliminación de los materiales se basó en su desarrollo vegetativo con alta emisión de guías y acame, la susceptibilidad a enfermedades (mustia hilachosa y antracnosis), además de ausencia de color comercial de grano.

Se efectuó selección negativa en las poblaciones con alta incidencia de patógenos. En el momento de cosecha, sólo se seleccionaron individualmente plantas que mostraban un ciclo vegetativo similar, o al máximo diez días más tardía, en relación con el testigo Sacapobres. Se separaron las plantas con vainas rojas y moradas, así como vainas amarillas. Posteriormente, se eliminaron las plantas que no mostraron semillas de color rojo de tono comercial. En la estación experimental, como referencias de tono rojo (testigo), se tomó la variedad Chirripó Rojo (que posee el color de grano rojo de más valor comercial entre las variedades mejoradas nacionales de Costa Rica), y Sacapobres con un valor intermedio. Los agricultores se basaron en su experiencia en comercializar frijol, para determinar cuáles de las líneas cumplían las exigencias del mercado en cuanto al tono del color rojo, tamaño y forma del grano.

\section{RESULTADOS Y DISCUSIÓN}

No se seleccionó ningún material de las poblaciones procedentes del CIAT (Cuadro 1), debido a su arquitectura de guía larga y acamada. Se eliminaron todas las familias provenientes de la cruza de Bribri con Sacapobres, por mostrar un hábito postrado de mucha emisión de guías, largo ciclo vegetativo y color rojo oscuro del grano. De la cruza Sacapobres con Cabécar, los agricultores seleccionaron 34 líneas en la estación experimental, que serán evaluadas en el año 2006 en las fincas de agricultores. Sólo de la cruza de Sacapobres con Tío Canela, los agricultores seleccionaron 20 familias en la etapa de selección en la estación experimental. En el año 2004 se seleccionaron dos líneas promisorias MPCR-202-26-1 y MPCR-202-30-2, 
Cuadro 1. Genealogía y proceso de selección participativa, de las poblaciones o familias, realizadas para la mejora de la variedad criolla Sacapobres. Alajuela, Costa Rica. 2001-2005.

\begin{tabular}{|c|c|c|c|c|c|c|c|c|c|}
\hline \multirow{3}{*}{$\begin{array}{l}\text { Institución } \\
\text { y país de } \\
\text { origen }\end{array}$} & \multirow{3}{*}{$\begin{array}{l}\begin{array}{l}\text { Año inicio } \\
\text { evaluaciones/ } \\
\text { localidad }\end{array} \\
\text { 2001, Estación } \\
\text { Experimental } \\
\text { Alajuela. }\end{array}$} & \multirow{3}{*}{\begin{tabular}{l} 
\# identi- \\
ficación \\
de la \\
mejora \\
\multicolumn{1}{c}{ I }
\end{tabular}} & \multirow{2}{*}{$\begin{array}{l}\text { Código } \\
\text { MR } 13546\end{array}$} & \multirow{2}{*}{$\begin{array}{l}\text { Genealogía } \\
\text { (Tío Canela } 75 \text { X (G 4691 X G 10909) F1) } \\
\text { F1 X Sacapobres Rojo/- (NN) C }\end{array}$} & \multicolumn{5}{|c|}{ 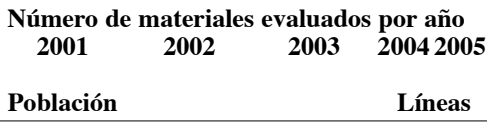 } \\
\hline & & & & & $22 / \mathrm{F} 3$ & $\begin{array}{l}3 \text { familias } \\
\text { (dos hábito } \\
\text { erecto y una } \\
\text { guía larga pa- } \\
\text { ra Chánguena) }\end{array}$ & $\begin{array}{l}35 \text { selec- } \\
\text { ciones } \\
\text { indivi- } \\
\text { duales }\end{array}$ & 0 & 0 \\
\hline & & & MR 13727 & $\begin{array}{l}\text { (Tío Canela } 75 \text { X (SAM } 3 \text { X G 10613) F1) } \\
\text { F1 X Sacapobres Rojo/- (NN) C }\end{array}$ & 8/F3 & 6 familias & 14 & 0 & 0 \\
\hline $\begin{array}{l}\text { CIAT, } \\
\text { Colombia }\end{array}$ & $\begin{array}{l}2001, \text { Estación } \\
\text { Experimental } \\
\text { Alajuela. }\end{array}$ & II & $\begin{array}{l}\text { BF } 14067 \\
\text { BF } 14068 \\
\text { MA } 14069 \\
\text { MA } 14070 \\
\text { MA } 14071 \\
\text { MA } 14072 \\
\text { MA } 14073\end{array}$ & $\begin{array}{l}\text { A } 774 \text { X Sacapobres Rojo/- } \\
\text { G } 21212 \text { X Sacapobres Rojo } \\
\text { A } 247 \text { X Sacapobres Rojo/- } \\
\text { G } 4691 \text { X Sacapobres Rojo/- } \\
\text { Mar } 1 \text { X Sacapobres Rojo/- } \\
\text { G } 10474 \text { X Sacapobres Rojo/- } \\
\text { A } 801 \text { X Sacapobres Rojo/- }\end{array}$ & $\begin{array}{l}1 / \mathrm{F} 2 \\
1 / \mathrm{F} 2 \\
1 / \mathrm{F} 2 \\
1 / \mathrm{F} 2 \\
1 / \mathrm{F} 2 \\
1 / \mathrm{F} 2 \\
1 / \mathrm{F} 2\end{array}$ & $\begin{array}{c}\text { Población } \\
1 / \mathrm{F} 3 \\
0 \\
0 \\
0 \\
0 \\
1 / \mathrm{F} 3 \\
\text { 1/F3 }\end{array}$ & $\begin{array}{l}0 \\
0 \\
0 \\
0 \\
0 \\
0 \\
0\end{array}$ & $\begin{array}{l}\text { Lí } \\
0 \\
0 \\
0 \\
0 \\
0 \\
0 \\
0\end{array}$ & $\begin{array}{r}\text { eas } \\
0 \\
0 \\
0 \\
0 \\
0 \\
0 \\
0\end{array}$ \\
\hline $\begin{array}{l}\text { Zamorano } \\
\text { Honduras }\end{array}$ & $\begin{array}{l}\text { 2001, ASOPRO } \\
\text { Veracruz de } \\
\text { Pejibaye }\end{array}$ & III & MPCR-202 & Sacapobres X Tío Canela & 1 & $\frac{\text { Familias }}{46}$ & 29 & $\frac{\text { Cínea }}{13}$ & 2 \\
\hline
\end{tabular}

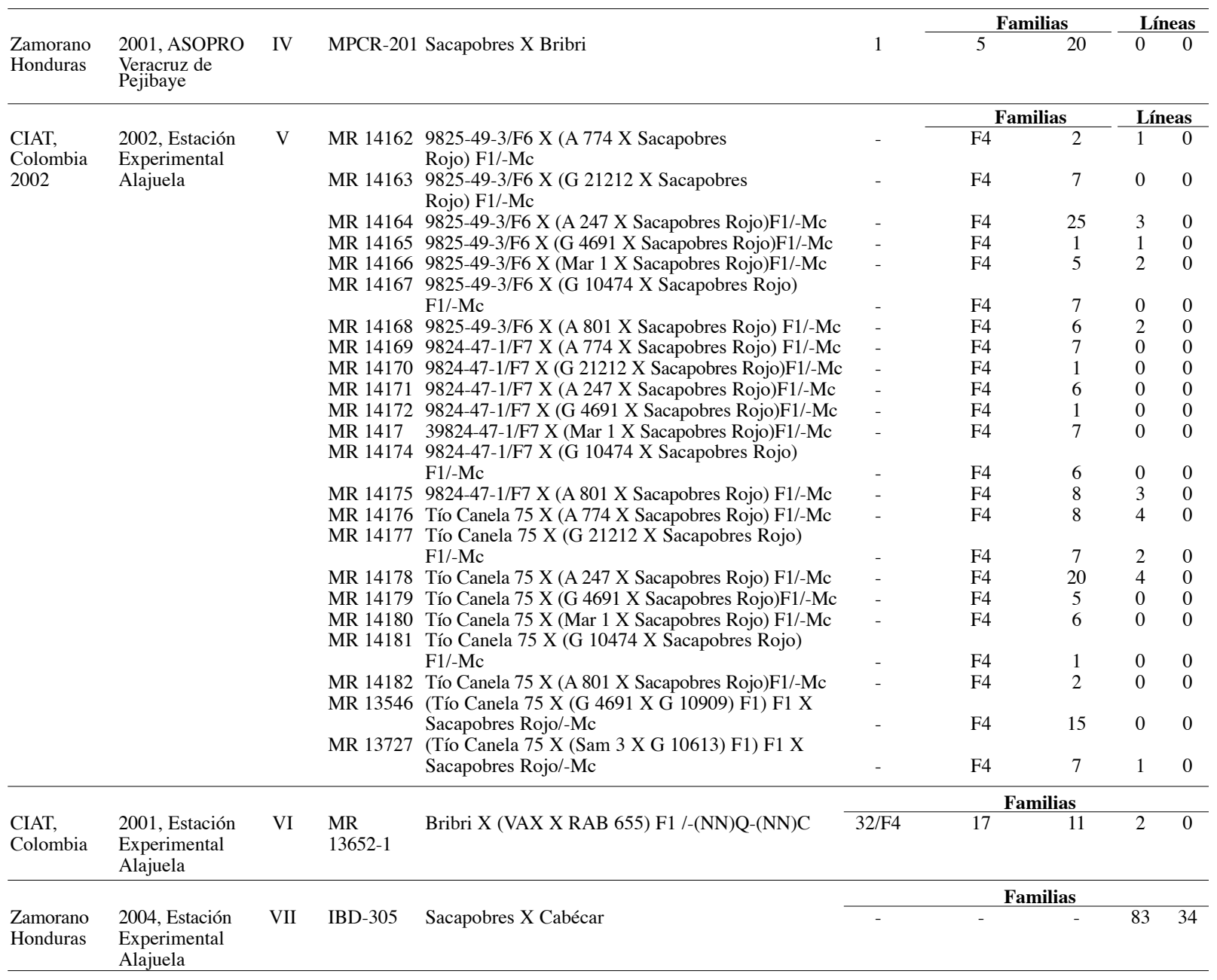


para llegar a la etapa de verificación al inicio del año 2006 y su posible liberación como variedad comercial a finales de este mismo año.

Cuadro 2. Secuencia de selección por sitio de evaluación (estación experimental y finca de agricultor), aplicado a la mejora genética participativa de la variedad criolla Sacapobres. Alajuela, Costa Rica. 2001-2005.

\begin{tabular}{|c|c|c|}
\hline $\begin{array}{l}\text { Año } \\
\text { inicio }\end{array}$ & $\begin{array}{l}\text { \# identificación } \\
\text { de la mejora }\end{array}$ & $\begin{array}{c}\text { Sitios de selección y } \\
\text { generación evaluada en } \mathbf{F P}^{2}\end{array}$ \\
\hline 2001 & I & $\begin{array}{l}\text { Estación experimental F } 3 \\
\text { Finca agricultor F } 4 \\
\text { Estación experimental F } 5\end{array}$ \\
\hline 2001 & II & $\begin{array}{l}\text { Estación experimental F } 2 \\
\text { Estación experimental F } 3\end{array}$ \\
\hline 2001 & III & Estación experimental F 4 \\
\hline 2001 & IV & $\begin{array}{l}\text { Finca agricultor F3 } \\
\text { Estación experimental F } 4\end{array}$ \\
\hline 2002 & V & $\begin{array}{l}\text { Estación experimental F } 4 \\
\text { Estación experimental F } 5 \\
\text { Estación experimental F } 6\end{array}$ \\
\hline 2001 & VI & $\begin{array}{l}\text { Estación experimental F } 4 \\
\text { Estación experimental F } 6\end{array}$ \\
\hline 2004 & VII & $\begin{array}{l}\text { Estación experimental F 4 } \\
\text { Estación experimental F 5 }\end{array}$ \\
\hline
\end{tabular}

\footnotetext{
1 Ver Cuadro 1.

${ }^{2}$ Las flechas indican las localidades, donde se efectuó la próxima selección de segregantes o líneas.
}

En el año 2005, 14 agricultores validaron en la Región Brunca, en parcelas semi comerciales (las parcelas variaron entre 500 a $1.500 \mathrm{~m}^{2}$ ), las dos únicas líneas seleccionadas de la variedad criolla Sacapobres, el rendimiento promedio general obtenido fue de 1136 $\mathrm{kg} / \mathrm{ha}, 918 \mathrm{~kg} / \mathrm{ha}$ y $887 \mathrm{~kg} / \mathrm{ha}$, de la MPCR-202-26-1, MPCR-202-30-2 y Sacapobres, respectivamente. La línea MPCR-202-26-1 fue estadísticamente superior a la línea MPCR-202-30-2 y a Sacapobres. La línea MPCR-202-30-2, fue más precoz y con mejor color comercial de grano. Todos los agricultores que participaron del proceso de validación se dejaron la semilla de las dos líneas, ya que consideraron que fueron superiores al Sacapobres (Delgado 20069 $)$.

Se necesitaron cuatro años para la selección de dos líneas promisorias (2001-2004), y se invertirán dos años más (2005-2006) en el proceso de validación antes de la liberación de una línea como variedad comercial.

El principal criterio de selección se basó en la arquitectura erecta (considerado como factor determinante en la selección de nuevas líneas promisorias para uso comercial). El tono del color de grano rojo, fue otro factor de selección (color rojo claro brillante). Los resultados obtenidos indican que la selección de los progenitores, debe dar énfasis a la selección de líneas o variedades con arquitectura erecta y de poca emisión de guías, ya que fue el principal factor que influyó en la selección de las líneas promisorias. Los agricultores al evaluar las líneas promisorias derivadas de Sacapobres, estuvieron más interesados en la arquitectura erecta con pocas guías y color de grano rojo comercial. Lo que indica que su objetivo es estabilidad en la producción y la venta de su cosecha a mejores precios.

De las dos líneas promisorias obtenidas de la cruza de Sacapobres con Tío Canela, la mayor preferencia se ha mostrado hacia la línea de arquitectura más erecta (MPCR-202-30-2), aunque su rendimiento fue inferior, pero de ciclo vegetativo más precoz. La arquitectura erecta da un ambiente menos favorable al desarrollo de patógenos, y permite el tránsito por el cultivo para la aplicación de agroquímicos.

9 DELGADO, J.A. 2006. Validación de dos líneas derivadas de la variedad criolla Sacapobres. Alajuela, Costa Rica. Escuela Agrícola Panamericana Zamorano. Comunicación personal. 
Cuadro 3. Principales criterios de selección empleadas por los agricultores y los investigadores, en la mejora genética participativa de la variedad criolla Sacapobres.

\begin{tabular}{ll}
\hline \multicolumn{1}{c}{ Investigadores } & \multicolumn{1}{c}{ Agricultores } \\
\hline Tolerancia a mustia hilachosa & $\begin{array}{l}\text { Arquitectura: pocas guías, muy ramificado, tallo } \\
\text { erecto, base del tallo grueso y raíces profusas. } \\
\text { vainas con mayor grado de impermeabilidad al } \\
\text { agua durante la época de cosecha. }\end{array}$ \\
Resistencia a antracnosis & $\begin{array}{l}\text { Resistencia a plagas y enfermedades, } \\
\text { Calidad culinaria: sabor, consistencia del caldo, }\end{array}$ \\
$\begin{array}{l}\text { Tolerancia al mosaico dorado } \\
\text { Tolerancia a la mancha angular }\end{array}$ & $\begin{array}{l}\text { Colojo grano, con base en la preferencia comercial. } \\
\text { Facilidad de trillado. }\end{array}$ \\
$\begin{array}{l}\text { Rendimiento (producción superior al testigo Sacapobres) } \\
\text { Tamaño, forma y color de grano, con base en la preferencia comercial } \\
\text { Adaptación a suelos de baja fertilidad }\end{array}$ & $\begin{array}{l}\text { Precocidad (ideal 60 días ciclo vegetativo) } \\
\text { Adaptación a condiciones locales (baja fertilidad). } \\
\text { Estabilidad en su arquitectura y rendimiento } \\
\text { entre localidades }\end{array}$ \\
$\begin{array}{l}\text { Rendimiento: mayor número de vainas, vainas más } \\
\text { largas, con más granos y llenado de vainas. }\end{array}$ \\
\hline
\end{tabular}

Se pudo mejorar la recopilación de la información en el proceso de FP, incorporando una antropóloga que fue estableciendo mecanismos de motivación, trabajo en grupo, captación de las ideas de los agricultores.

La participación de las ASOPROS, fue determinante en lograr una mayor cobertura de sitios y épocas de evaluación, disminuir los costos de la investigación en relación con el FC, debido a que las ASOPROS asumieron la mayoría de los costos de mano de obra y brindaron el área experimental en sus fincas. Otro factor determinante fue la mejor capacidad de convocatoria de la ASOPRO para la divulgación de la información obtenida en los días de campo, a la comunidad de agricultores, e iniciar el incremento de semilla de las líneas que consideran promisorias.

En Costa Rica, el FP supera al FC, en la adopción de variedades por los pequeños productores. La variedad comercial en Costa Rica de mayor cobertura en área de siembra (procedente de FC) fue la Brunca, pero bajo producción mecanizada. Con el FP se está aprovechando mejor el recurso humano y financiero, y no se corre el riesgo de seleccionar líneas o variedades no adecuadas a las necesidades de los productores. Con el FC la adopción sería lenta o nula con los pequeños productores y la disponibilidad de semilla sólo limitada a un sistema formal de producción de semilla.

La evaluación participativa en estación experimental, en particular cuando se dispone de gran cantidad de material segregante, resultó provechosa, debido a los mejores controles en el ambiente (uniformidad del suelo, suelos de poca gradiente, drenajes, riego, áreas de secado y equipo de proceso poscosecha para pequeñas parcelas), que minimizan los riesgos de pérdida de plantas. También resultó provechoso para ver efecto ambiental (sitio con condiciones diferentes a los sitios de siembra comercial), más facilidad para establecer parcelas de mayor tamaño, con el objetivo de medir potencial de producción.

Agricultores de otras regiones que participaron del FP, adoptaron rápidamente este proceso. Un ejemplo se evidenció con los agricultores de Pueblo Nuevo, Región Huetar Norte, que en el transcurso del primer año de conocer el proceso de FP, establecieron los comités de investigación, seleccionaron agricultores investigadores, fincas donde se evaluarían los ensayos, y debido a su nuevo esquema de trabajo en FP, lograron que les donaran una finca para dedicarla a la investigación. Como es una zona donde participa más la mujer en la producción de campo, se evidenció un enriquecimiento de la metodología al incorporar más factores de selección.

La mejora genética bajo la metodología de FP, mostró su efectividad en la selección de las mejores líneas para los agricultores (Hernández y Araya 2001). Cuando los investigadores no pudieron asistir a las evaluaciones de campo, los agricultores, tomaron las notas. En esta mejora genética de la variedad criolla Sacapobres, los agricultores cada vez más se convirtieron en actores en la mejora genética y no en un prestatario de lotes. Además, los agricultores conocieron 
desde etapas iniciales los materiales, y las dos nuevas líneas de Sacapobres. Varios agricultores se motivaron a sembrar estas líneas promisorias para incrementar semilla, y disponer a corto plazo, según su opinión, de un mejor material para producción y comercialización (antes el productor conocía las nuevas variedades el día que se hacia la liberación oficial). Esto reduce los costos de producción y facilita el proceso de adopción, o más bien lo anticipa.

Investigadores en mejora genética del frijol común del CIAT, actualmente están orientando parte de la estrategia de mejora genética por hibridación en frijol común, con base en los criterios de selección indicados por los agricultores. Las nuevas líneas con tolerancia a sequía, procedentes del CIAT, muestran arquitectura erecta, similar a la variedad Bribri, lo que indica que a corto plazo los agricultores dispondrán de una gama más amplia de líneas. Esto ha permitido mejorar el enfoque de la investigación internacional hacia la necesidad real del productor, donde las variedades criollas podrían ser mejoradas con nuevos progenitores que aporten arquitectura erecta.

Con esta metodología de FP, se observó que los agricultores se responsabilizaron de lo que ocurriera en el sitio de experimentación; también se encontró que su participación resultó ser cada vez más intensa en el proceso, son reconocidos a nivel local como conocedores de las nuevas líneas o potenciales variedades, por lo que constantemente son consultados por los demás agricultores sobre la calidad de cualquier variedad.

En los días de campo y evaluación, en los cuales otros agricultores visitan los ensayos, los visitantes dieron reconocimiento a las ASOPROs sobre sus trabajos. Los técnicos observaron la capacidad real de los agricultores de participar activamente en la investigación y, contrario a lo que creían, concluyeron que los agricultores son compatibles en el trabajo de mejora genética, con los investigadores; y además, su participación ha permitido incrementar la eficiencia y obtener resultados de calidad que responden a sus necesidades reales.

La generación de nuevo material promisorio por medio de la hibridación con el empleo de la variedad Sacapobres, se vio limitada por los progenitores empleados, con excepción del Tío Canela. Se espera con nuevos progenitores mejorar la arquitectura y rescatar precocidad. La combinación manejo agronómico y la obtención de nuevas variedades de arquitectura erecta, precoces, de mayor tolerancia a los patógenos, es el reto para una producción más amigable con el ambiente, y rentable.

\section{AGRADECIMIENTOS}

Se agradece la valiosa colaboración financiera brindada a esta investigación por: -el Fondo de Desarrollo Noruego // Utviklingsfondet y a la Unión Europea, -ACSUR Las Segovias. -Al Programa de Fitomejoramiento Participativo en Mesoamérica (FP-MA), al cual pertenecemos desde su origen y ha sido enriquecedor en el fortalecimiento de la estrategia de mejora genética participativa. A las ASOPROS de Concepción de Pilas, Veracruz y El Águila, y la Cooperativa Pueblo Nuevo de Upala, por el alto grado de empoderamiento en el proceso de FP, al pasar de colaboradores a gestores de nuevas investigaciones en mejora genética del frijol, que incluye además la producción de semilla local de las líneas promisorias.

\section{LITERATURA}

ALMEKINDERS, C. J. M.; ELINGS, A. 2001. Collaboration of farmers and breeders: Participatory crop improvement in perspective. Euphytica 122: 425-438.

ARAYA, R.; GONZÁLEZ W. 1987. La investigación en campos de agricultores sobre frijol tapado en Costa Rica. In: Wolley, J. N. comp. La investigación de frijol en campos de agricultores de América Latina. Memorias de un Taller. Cali, Colombia. Centro Interancional de Agricultura Tropical (CIAT). Documento de trabajo \# 27. p. 190-197.

ARAYA, R. 1998. Mejoramiento genético de frijol mesoamericano en Costa Rica. In: Taller Internacional de Mejoramiento Genético de Frijol Negro Mesoamericano. Programa Cooperativo Regional de Frijol para Centroamérica, México y El Caribe. Veracruz, México. p. 55-84. 
ARAYA R.; HERNÁNDEZ, J.C. 2001. Fitomejoramiento participativo en la Región Brunca de Costa Rica. In: Memorias de la Conferencia Internacional sobre Futuras estrategias para implementar Mejoramiento Participativo en los Cultivos de las Zonas Altas en la Región Andina. Editor Daniel Danial. Quito, Ecuador. Produgrafi Center. 197 p.

ARAYA, R.; HERNÁNDEZ, J.C.; ELIZONDO, F.I. 2002. El fitomejoramiento participativo en la selección de líneas promisorias de frijol para grupos organizados de pequeños productores de la Región Brunca, Costa Rica. I. In: VI Taller Anual de Resultados de Investigación y Transferencia de Tecnología. Programa de Investigación y Transferencia de Tecnología Agropecuaria - Frijol (PITTA-Frijol). San José, Costa Rica. 35-40 p.

ASHBY, J. 1993. Manual para la evaluación de tecnologías con productores. CIAT, Cali, Colombia. 114 p.

ASHBY, J.; GRACIA, T.; GUERRERO, M.P.; QUIRÓS, C.A.; ROA, J.I.; BELTRÁN, J.A. 1995. Institutionalising farmer participation in adaptive technology testing with the CIAL. Agricultural Research and Extensión Network 57 (Londres): 43 p.

HERNÁNDEZ, J.C.; ARAYA, R. 2003. Cabécar, variedad de frijol de grano rojo para Costa Rica. In: VII Reunión Anual del Sector Frijolero de Costa Rica. San José, Costa Rica. SIEDIN, Universidad de Costa Rica. p. 21-28.
HERNÁNDEZ, J.C.; ARAYA, R. 2004. Logros de la implementación del fitomejoramiento participativo (FP) en frijol en Costa Rica. In: VIII Reunión Anual del Sector Frijolero de Costa Rica. San José, Costa Rica. SIEDIN Universidad de Costa Rica. p. 13-24.

HOCDÉ, H.; HERNÁNDEZ, J. C.; ARAYA, R.; BERMÚDEZ, A. 1999a. Proceso de Fitomejoramiento Participativo con frijol en Costa Rica: la historia de "Sacapobres". In: Fitomejoramiento Participativo en América Latina y el Caribe. Memorias de un Simposio Internacional, Quito, Ecuador. Agosto 31 - Septiembre 3. ISSN 958-694-031-4 CD. http: //www.prgaprogram.org/prga.

HOCDÉ, H.; HERNÁNDEZ, J. C.; QUIRÓS, E.; TINOCO, R. 1999b. El Viaje Centroamericano de Orifica Turipaná" Fitomejoramiento Participativo en América Latina y el Caribe. Memorias de un Simposio Internacional, Quito, Ecuador. Agosto 31 - Septiembre 3. Disponible en: http: //www.prgaprogram.org/prga.

ROSAS, J.C. 2001. Aplicación de metodologías participativas para el mejoramiento genético de frijol en Honduras. Agron. Mesoam. 12(2): 219-228.

ROSAS, J.C.; GALLARDO, O.; JIMÉNEZ, J. 2003. Mejoramiento genético del frijol común mediante enfoques participativos en Honduras. Agron. Mesoam. 14(1): 01-09. 